\title{
TETRACICLINAS E GLICILCICLINAS: UMA VISÃO GERAL
}

\section{Elene Cristina Pereira-Maia, Priscila Pereira Silva e Wagner Batista de Almeida}

Departamento de Química, Instituto de Ciências Exatas, Universidade Federal de Minas Gerais, Campus Pampulha, 31270-901

Belo Horizonte - MG, Brasil

Hélio Ferreira dos Santos e Bruna Luana Marcial

Departamento de Química, Instituto de Ciências Exatas, Universidade Federal de Juiz de Fora, Campus Martelos, 36036-330 Juiz

de Fora - MG, Brasil

Reinaldo Ruggiero e Wendell Guerra*

Instituto de Química, Universidade Federal de Uberlândia, Campus Santa Mônica, 38400-902 Uberlândia - MG, Brasil

Recebido em 18/5/09; aceito em 4/9/09; publicado na web em 22/2/10

\begin{abstract}
TETRACYCLINES AND GLYCYLCYCLINES: AN OVERVIEW. Tetracyclines exhibits activity to a broad range of Gram-negative and Gram-positive bacteria and this fact allied to the low toxicity, low cost, and the advantage of administration by oral route led to their indiscriminate use, which caused the appearance of bacterial resistance to these agents, wich has restricted its clinical utility, though new applications have emerged. On the other hand, the glycylcyclines, semi-synthetic products are similar to tetracyclines, which are active against many bacteria resistant to tetracycline and other classes of antibiotics. The purpose of this paper is to give an overview of this important class of antibiotics focusing on its coordination chemistry and possible applications.
\end{abstract}

Keywords: tetracyclines; glycylcyclines; antibacterial activity.

\section{INTRODUÇÃO}

A descoberta do primeiro membro da família das tetraciclinas em 1945 por Benjamin Duggar, a clortetraciclina, que é um produto da fermentação natural de uma bactéria do solo, Streptomyces aureofaciens, provocou uma corrida na pesquisa e obtenção de novas tetraciclinas com grande sucesso. Assim, de 1950 a 1970, vários membros da família das tetraciclinas haviam sido desenvolvidos, uns como produtos naturais, outros como produtos semissintéticos e, neste mesmo período, as tetraciclinas figuraram entre os antibióticos mais usados nos Estados Unidos. ${ }^{1-3}$

Após a descoberta da minociclina em 1972, um longo tempo se passou sem que novas tetraciclinas fossem descobertas até que, no ano de 1993, as glicilciclinas, foram sintetizadas. As glicilciclinas são produtos semissintéticos análogos às tetraciclinas, que são ativos contra inúmeras bactérias resistentes às tetraciclinas e a outras classes de antibióticos. ${ }^{4}$ Em 2005, o composto denominado tigeciclina (tygacil $^{\mathrm{TM}}$ ), uma glicilciclina derivada da minociclina, que possui um grupo glicilamido na posição C9, foi aprovado para uso clínico pela FDA e, recentemente, o composto denominado PTK-0796, um derivado semissintético da minociclina, tem chamado a atenção, pois entrou em fase I de testes clínicos. ${ }^{5,6}$

Tetraciclinas possuem diversas propriedades favoráveis, tais como amplo espectro de ação, baixa toxicidade, baixo custo, e podem ser, na maioria dos casos, administradas por via oral. ${ }^{1,2}$ Devido a essas propriedades, tetraciclinas em geral têm sido utilizadas indiscriminadamente, o que tem levado ao aparecimento de resistência em um grupo variado de bactérias, principalmente às tetraciclinas de primeira geração, descobertas no período compreendido entre 1950 e 1970, e isto provocou e tem provocado restrições na utilidade clínica destes compostos. ${ }^{3}$ No entanto, tetraciclinas ainda são bastante úteis na clínica médica e têm sido usadas no tratamento de diversos tipos de infecção. ${ }^{7-9}$ Além do uso em humanos, tetraciclinas são utilizadas na terapia animal para tratar infecções e promover o crescimento. ${ }^{7}$ Além

*e-mail: wg@iqufu.ufu.br disso, tigeciclina e minociclina têm sido indicadas no tratamento de MRSA (Staphyloccocus aureus resistente à meticilina) sendo um dos poucos antibióticos ativos contra essa linhagem disponíveis atualmente. ${ }^{10}$ Em relação às propriedades farmacológicas destes compostos, tetraciclinas possuem uma série de propriedades não antibióticas e há vários estudos sendo conduzidos no sentido de se usar tetraciclinas no tratamento de doenças não infecciosas, tais como artrite reumatóide e câncer. ${ }^{811}$ Nesse contexto, análogos como doxiciclina têm sido avaliados na quimioterapia do câncer, induzindo apoptose diretamente ou combinados com agentes antitumorais conhecidos. ${ }^{12,13} \mathrm{~A}$ principal vantagem da ação sinérgica das tetraciclinas (especialmente o análogo doxiciclina) é a tolerância razoável com relação à dose do fármaco, permitindo a redução na administração do agente principal (por exemplo, a cisplatina). ${ }^{14}$

Além das tetraciclinas tradicionais, o grande interesse da aplicação dessa classe de moléculas no tratamento de tumores tem direcionado os estudos para um novo conjunto de substâncias análogas, conhecidas como CMT (Chemically Modified Tetracyclines). As CMTs possuem o esqueleto básico das tetraciclinas, com a principal alteração sendo a remoção do grupo dimetilamino (DMA) da posição C4. ${ }^{12}$ Essa modificação química elimina a ação antibacteriana e, consequentemente, potencializa efeitos secundários. Especificamente no caso das CMTs, o foco terapêutico é prevenir a angiogênese e a metástase, através da inibição de enzimas conhecidas como MMP (matrix metalloproteinase). Um dos análogos mais promissores nesse sentido é o 4-dedimetilamino sanciclina, conhecido como CMT-3 ou Col-3. ${ }^{12} \mathrm{O}$ mecanismo geral de ação de inibidores das MMPs é parcialmente conhecido, entretanto, em função da complexidade do processo de metástase e diversidade das MMPs, os estudos existentes ainda estão em fase pré-clínica. ${ }^{12}$

Considerando os parâmetros farmacocinéticos para as tetraciclinas utilizadas na clínica médica, somente a tigeciclina não é administrada por via oral, sendo oxitetraciclina, doxiciclina e minociclina administradas tanto por via oral, quanto por via parenteral. ${ }^{6,15} \mathrm{Em}$ relação à absorção, doxiciclina e minociclina são bem absorvidas pelo organismo e alguns autores têm atribuído uma completa absor- 
ção desta última. Já clortetraciclina, oxitetraciclina e tetraciclina são caracterizadas por uma má absorção, principalmente após a ingestão de alimentos. Como exemplo, a absorção da clortetraciclina está na faixa entre 25 e $30 \% .{ }^{6}$ A porcentagem da droga que não é absorvida cresce à medida que a dose é aumentada, sendo que a maior parte da absorção ocorre no estômago e no intestino delgado superior. Tetraciclinas, em relação ao tempo de meia vida no organismo $\left(t_{1 / 2}\right)$, podem ser divididas em tetraciclinas de ação curta, média e longa. Assim, clortetraciclina, oxitetraciclina e tetraciclina são drogas de ação curta com tempo de meia vida igual a 6,8 e $9 \mathrm{~h}$, respectivamente. Demeclociclina é uma droga de ação média (12 h) e, por fim, doxiciclina, minociclina e tigeciclina são drogas de ação longa com tempo de meia vida superior a 15 h. ${ }^{6}$ Devido aos parâmetros farmacocinéticos não muito favoráveis e à resistência apresentada por diversas linhagens bacterianas, a clortetraciclina e a oxitetraciclina não têm sido mais prescritas para tratamento de infecções em humanos em diversos países. ${ }^{7}$ Tetraciclina, minociclina e doxiciclina têm sido mais prescritas para tratamento de infecções em humanos e, no caso da doxiciclina e da minociclina, isto se deve aos menores efeitos colaterais e ao reduzido número de doses requerido por dia de tratamento. ${ }^{8}$

A Figura 1 mostra algumas das principais tetraciclinas usadas na clínica médica e em fase de testes clínicos.

\section{RELAÇÕES ENTRE ESTRUTURA E ATIVIDADE E QUÍMICA DE COORDENAÇÃO DAS TETRACICLINAS}

As relações entre estrutura química e atividade das tetraciclinas são estudadas desde a década de 60. Em 1965, Colaizzi et al. ${ }^{16}$ desenvolveram um estudo utilizando como modelo para o sítio receptor das tetraciclinas a enzima NADH-citocromo-c oxirredutase. Esse trabalho foi baseado em informações anteriores de que o modo de ação das tetraciclinas poderia estar relacionado com a interferência no processo de fosforilação oxidativa, inibindo o sistema de transporte de elétrons da célula e, consequentemente, a formação de ATP. A relevância dos resultados obtidos por Colaizzi et al. está na identificação de grupos e estereoquímica dos centros quirais essenciais para a atividade biológica. De acordo com as conclusões obtidas, a configuração absoluta natural do átomo de carbono C4 (Figura 1) é requisito essencial para a ação farmacológica desses compostos. A presença do grupamento amida em C2 foi também considerada como aspecto estrutural necessário para a ação biológica das tetraciclinas. Outra observação importante relacionada ao aumento da potência inibitória enzimática foi a ausência dos grupos metila e hidroxila na posição C6. Em princípio, as observações e hipóteses levantadas no trabalho de Colaizzi et al.foram correlacionadas com informações obtidas de estudos envolvendo inibição do crescimento celular. Atualmente, ${ }^{2,7}$ novos aspectos que versam sobre a relação estrutura e atividade têm surgido. Incluindo glicilciclinas, sabe-se que a manutenção do núcleo tetracíclico (anéis A, B, C e D), a influência dos substituintes nas posições $\mathrm{C} 7, \mathrm{C} 8$ e C9, a conservação do sistema ceto-enólico (posições C11, C12 e C12a) e e a configuração $\alpha$ nas posições 4a e 12a são essenciais para a manutenção da atividade farmacológica das tetraciclinas e, neste aspecto, a estrutura da 6-desoxi6-desmetiltetraciclina pode ser considerada uma estrutura mínima para a manutenção da atividade farmacológica das tetraciclinas. ${ }^{7}$

Com o objetivo de obter tetraciclinas que contornassem o problema da resistência apresentada pelas primeiras tetraciclinas, no início dos anos de 1990, um intenso programa foi desenvolvido por pesquisadores da Lederle Laboratories e o resultado destes esforços foi o desenvolvimento do composto denominado tigeciclina, entre outras glicilciclinas. Tigeciclina, um derivado semissintético da minociclina, que contém o grupo N,N-dimetilglicilamido na posição $\mathrm{C} 9$, apresenta ótima atividade antibacteriana contra bactérias resistentes às primeiras tetraciclinas. ${ }^{1,2}$
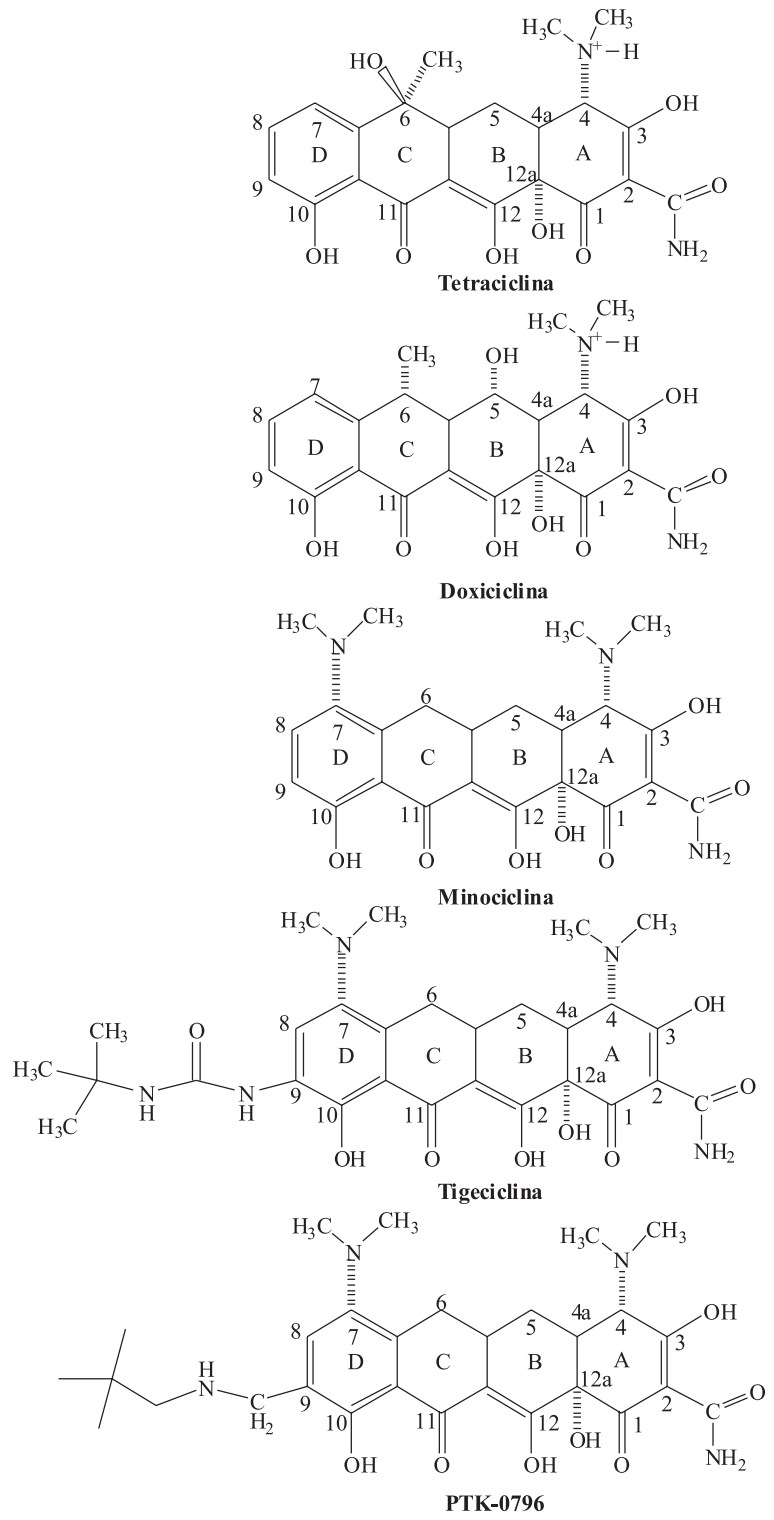

Figura 1. Estruturas das principais tetraciclinas usadas na clínica médica e em fase de testes clínicos (PTK-0796)

Mais recentemente, pesquisadores da Paratek Pharmaceuticals anunciaram a entrada do composto intitulado PTK-0796 em fase I de testes clínicos. Este composto contém o grupo dimetil-propil-amino na posição C9 da minociclina e também tem apresentado amplo espectro de atividade antibacteriana.

Com estes resultados, novas relações entre estrutura e atividade têm surgido, indicando que a substituição na posição C9 das tetraciclinas, principalmente da minociclina, é bastante promissora na obtenção de novos antibióticos da família das tetraciclinas.

Por outro lado, também recentemente foi mostrado, por nosso grupo de pesquisa, que a coordenação de platina(II) à tetraciclina e doxiciclina via anel A resulta em compostos ativos contra linhagens de bactérias resistentes à tetraciclina e a outros antibióticos. ${ }^{17,18}$ Este resultado é bastante interessante, pois introduz a coordenação de metais às tetraciclinas como um novo parâmetro na busca de compostos capazes de reverter a resistência bacteriana. A Figura 2 mostra os principais aspectos da relação estrutura $\mathrm{x}$ atividade.

Em relação à química de coordenação, é sabido que tetraciclinas se coordenam a íons metálicos presentes no meio biológico, sendo que a sua biodisponibilidade é afetada pela coordenação. ${ }^{19}$ Além da 


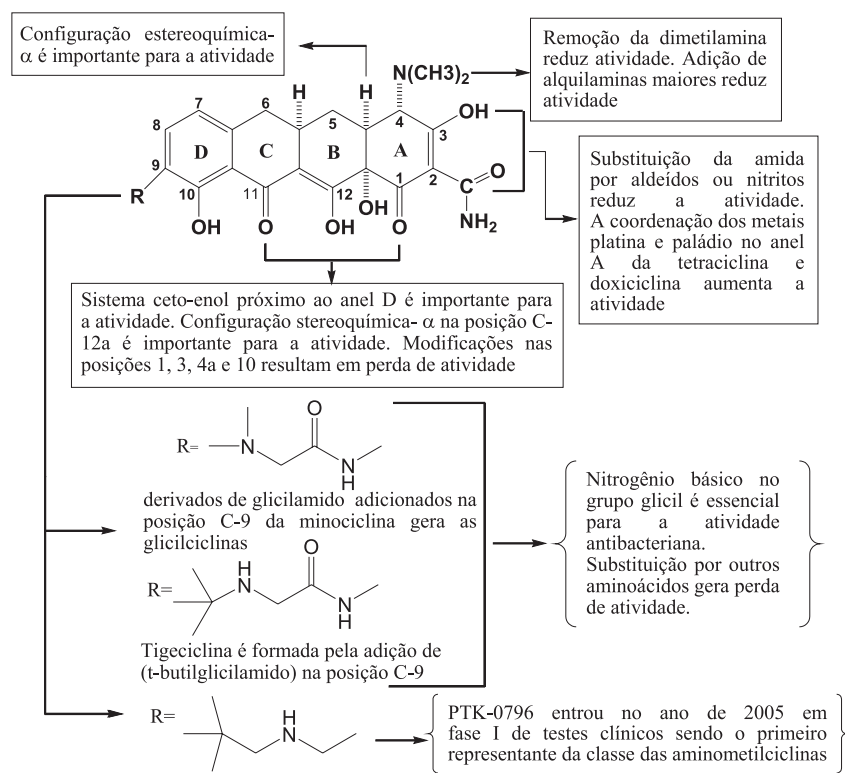

Figura 2. Aspectos relacionados à relação entre estrutura e atividade para tetraciclinas

importância farmacológica das tetraciclinas, estas drogas possuem uma estrutura química muito interessante, podendo formar quelatos em várias posições da molécula devido à presença de vários grupos doadores $(\mathrm{N}, \mathrm{O})$. Os sítios de coordenação incluem os oxigênios em C10-C12, o oxigênio enólico em C3 e os nitrogênios em C4 e no grupo amida do anel A. A tetraciclina possui três prótons dissociáveis, um no grupo enol em $\mathrm{C} 3$, outro no sistema ceto-fenólico em $\mathrm{C} 10-\mathrm{C} 12$ e outro no grupo dimetilamônio em $\mathrm{C} 4$, com valores de pKa 3,5; 7,7 e 9,3, respectivamente. ${ }^{17,20}$ Vale ressaltar que a minociclina possui um grupo dimetilamina adicional na posição C7 e, consequentemente, apresenta um valor adicional de pKa e um sítio a mais de coordenação. É importante mencionar que essa característica é distinta nas CMTs, as quais apresentam apenas dois pKa, relacionados aos sítios $\mathrm{O} 3$ e O12. ${ }^{21}$ Curiosamente, na literatura ainda não há relatos de complexos metálicos isolados no estado sólido contendo minociclina ou glicilciclinas.

Por causa da importância biológica das tetraciclinas, suas interações com íons metálicos, principalmente cálcio(II) e magnésio(II), têm sido estudadas, utilizando-se principalmente as técnicas de RMN, dicroísmo circular e UV-Vis. Entretanto, como as estruturas das tetraciclinas são particularmente complexas, com grande número de sítios potencialmente complexantes, a caracterização estrutural é uma tarefa difícil, levando a muita controvérsia na localização dos sítios de coordenação envolvidos. ${ }^{22-41}$ Nesse contexto, estudos teóricos têm sido realizados por alguns de nós, relacionados à interação do derivado 5a,6-anidrotetraciclina (AHTC) com cátions metálicos. ${ }^{42-46}$ Esses trabalhos têm auxiliado os experimentalistas nas propostas para os possíveis sítios de coordenação, como evidenciado nos trabalhos de Wessels et al. ${ }^{47}$ e Vogler et al..${ }^{40}$ envolvendo complexos de AHTC com $\mathrm{Mg}(\mathrm{II})$ e $\mathrm{Pt}(\mathrm{II})$, respectivamente.

Outros estudos envolvendo a coordenação de metais de transição e aqueles da série dos lantanídeos têm sido realizados, principalmente, na tentativa de se obter complexos com propriedades luminescentes e com atividade antibacteriana. ${ }^{32,37}$ Estudos referentes à interação da tetraciclina com o DNA em presença de íons cobre(II) indicaram que a adição destes íons aumenta a porcentagem de ligação da tetraciclina ao DNA e que o complexo de tetraciclina formado com cobre provoca quebra na fita do DNA. ${ }^{33,34} \mathrm{~A}$ interação entre o complexo formado e a molécula de DNA ocorre via intercalação e, em consequência, há uma desestabilização da estrutura do DNA. ${ }^{33}$ Neste contexto, sabese que complexos metálicos contendo tetraciclinas podem interagir com o DNA por intercalação, ${ }^{32,40}$ enquanto que trabalhos posteriores sugerem que tetraciclinas livres não podem. ${ }^{24}$

Apesar das interações de metais com tetraciclinas terem sido extensivamente estudadas, poucos complexos metálicos de tetraciclinas foram isolados no estado sólido e apenas um complexo de mercúrio com a oxitetraciclina teve sua estrutura determinada por difração de raios X, Figura $3 .{ }^{35}$

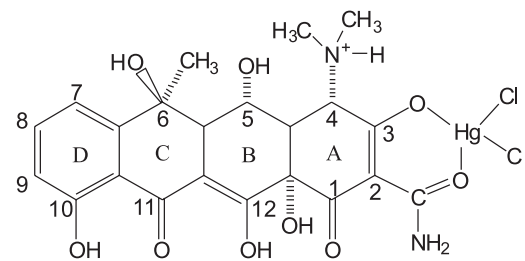

Figura 3. Complexo de mercúrio contendo oxitetraciclina

A Tabela 1 mostra alguns complexos sintetizados e caracterizados no estado sólido e, como se pode observar, diferentes sítios de coordenação e diferentes estruturas foram propostas. Uma explicação para tal diversidade de sítios de coordenação e estequiometrias se refere à natureza do íon metálico e às condições experimentais utilizadas, uma vez que as tetraciclinas sofrem mudanças conformacionais, dependendo do $\mathrm{pH}$ e da polaridade do meio. ${ }^{48}$ Além disto, dependendo do meio, diferentes espécies tautoméricas de tetraciclinas irão predominar e diferentes sítios de coordenação estarão disponíveis. ${ }^{20}$

Recentemente, complexos de Pt(II) e Pd(II) com tetraciclinas têm sido descritos na literatura. O primeiro trabalho foi apresentado por Vogler et al.,${ }^{40}$ os quais sintetizaram e caracterizaram o complexo de $\mathrm{Pt}$ (II) com o derivado AHTC. Esses autores propuseram a coordenação no anel A, sem a definição dos grupos envolvidos. Em um trabalho posterior, Chartone-Souza et al. ${ }^{17}$ relataram um estudo experimental sistemático da síntese e caracterização do complexo de Pt(II) com a molécula de tetraciclina. Nesse estudo, as análises espectroscópicas (principalmente $\mathrm{RMN}{ }^{1} \mathrm{H}$ ) mostraram que a coordenação ocorre no sítio O3-Oam do anel A. Essa proposta foi sustentada por cálculos teóricos realizados por Dos Santos et al. ${ }^{46}$ para o sistema AHTC-Pt(II), os quais mostraram resultados espectroscópicos e termodinâmicos indicando a coordenação em O3-Oam ou Oam-O1. Nesse contexto, os mesmos autores mostraram recentemente ${ }^{49}$ que o sítio de coordenação mais favorável para o derivado CMT-3, considerando Pt(II), é também aquele contendo os grupo $\mathrm{O} 3$ e Oam, sendo diferente apenas em meio ácido onde o sítio O3 não se encontra disponível. Nessa condição a coordenação ocorre preferencialmente no sítio O1-O12. Um outro resultado interessante nesse trabalho foi mostrar que a coordenação em 011-O12 (sítio de coordenação comum para íons alcalinos e alcalinos terrosos) é consideravelmente favorável em $\mathrm{pH}>10$, apesar da coordenação em O1-Oam representar a estrutura mais provável. ${ }^{49}$

Um resultado interessante, obtido por de Paula F. C. et al., foi que complexos de Pd(II) da tetraciclina e da doxiciclina apresentam atividade citotóxica. ${ }^{36}$ Antes, nós havíamos mostrado que os mesmos compostos eram ativos em linhagens de bactérias resistentes à tetraciclina. ${ }^{39} \mathrm{~A}$ hipótese de utilizar os complexos de tetraciclina-Pt(II) na quimioterapia do câncer é reforçada pelo estudo teórico realizado recentemente por Dos Santos et al..${ }^{50}$ no qual mostraram que a reatividade do complexo [Pt(AHTC $\left.) \mathrm{Cl}_{2}\right]$ frente a diversos nucleófilos é similar à da cisplatina.

Estudos referentes aos compostos de coordenação contendo tetraciclinas como ligantes têm demonstrado que estes compostos podem vir a ser úteis, tanto na clínica médica quanto na área tecnológica. Complexos contendo tetraciclinas são frequentemente luminescentes e podem ter aplicações em fototerapia e como son- 
Tabela 1. Complexos metálicos utilizando tetraciclinas como ligantes

\begin{tabular}{|c|c|c|c|c|c|}
\hline Reagentes utilizados e Estequiometria & Solvente & $\mathrm{pH}$ & $\begin{array}{l}\text { Produto obtido: } \\
\text { estequiometria }\end{array}$ & Sítio de coordenação & Ref. \\
\hline $\mathrm{LnCl}_{3}+\mathrm{TC} . \mathrm{HCl}$ & $\mathrm{MeOH}$ & 7.0 & {$\left[\mathrm{Ln}(\mathrm{TC}) \mathrm{Cl}_{3}\right] \cdot 2 \mathrm{H}_{2} \mathrm{O}$} & $\mathrm{O}_{10}, \mathrm{O}_{11}$ e $\mathrm{O}_{12}$ & 37 \\
\hline $\mathrm{NiCl}_{2} \cdot 6 \mathrm{H}_{2} \mathrm{O}+2.1 \mathrm{TC} . \mathrm{HCl}$ & $\mathrm{MeOH}$ & 7.5 & {$\left[\mathrm{Ni}(\mathrm{TC})_{2}\left(\mathrm{H}_{2} \mathrm{O}\right)_{2}\right]$} & Oxigênios-anel A & 38 \\
\hline $\mathrm{CoCl}_{2} \cdot 6 \mathrm{H}_{2} \mathrm{O}+2.2 \mathrm{ATC} . \mathrm{HCl}$ & $\mathrm{MeOH}$ & 8.0 & {$\left[\mathrm{Co}(\mathrm{ATC})_{2}\left(\mathrm{H}_{2} 0\right)_{2}\right]$} & Oxigênios-anel A & 38 \\
\hline $\mathrm{K}_{2} \mathrm{PdCl}_{4}+\mathrm{TC} \cdot \mathrm{HCl}$ & $\mathrm{H}_{2} \mathrm{O}$ & N.F & {$\left[\mathrm{Pd}(\mathrm{TC}) \mathrm{Cl}_{2}\right] \cdot 2 \mathrm{H}_{2} \mathrm{O}$} & $\mathrm{O}_{3} \mathrm{e} \mathrm{O}_{\text {amida }}$ & 39 \\
\hline $\mathrm{K}_{2} \mathrm{PtCl}_{4}+\mathrm{TC} . \mathrm{HCl}$ & $\mathrm{H}_{2} \mathrm{O}$ & N.F & {$\left[\mathrm{Pt}(\mathrm{TC}) \mathrm{Cl}_{2}\right]$} & $\mathrm{O}_{3} \mathrm{e} \mathrm{O}_{\text {amida }}$ & 17 \\
\hline${ }^{*} \mathrm{~K}_{2} \mathrm{PtCl}_{4}+4.1 \mathrm{TC}$ & Ac. acético & N.F & {$\left[\mathrm{Pt}(\mathrm{ATC}) \mathrm{Cl}_{2}\right]$} & Anel A & 40 \\
\hline $\mathrm{K}_{2} \mathrm{PtCl}_{4}+\mathrm{DOX} . \mathrm{HCl}$ & $\mathrm{H}_{2} \mathrm{O}$ & N.F & {$\left[\mathrm{Pt}(\mathrm{DOX}) \mathrm{Cl}_{2}\right] \cdot 2 \mathrm{H}_{2} \mathrm{O}$} & $\mathrm{O}_{3} \mathrm{e} \mathrm{O}_{\text {amida }}$ & 18 \\
\hline${ }^{*} \mathrm{Re}(\mathrm{CO}) \mathrm{Cl}+\mathrm{OTC} . \mathrm{HCl}$ & Tolueno & N.F & {$\left[\mathrm{Re}(\mathrm{OTC})(\mathrm{CO})_{3} \mathrm{Cl}\right]$} & $\mathrm{O}_{11}$ e $\mathrm{O}_{12}$ & 32 \\
\hline${ }^{* *} 1.4 \mathrm{Cu}\left(\mathrm{ClO}_{4}\right)_{2}+2.5 \mathrm{TC}$ & EtOH- Teof & N.F & {$\left[\mathrm{Cu}(\mathrm{TC})_{2}\left(\mathrm{ClO}_{4}\right)_{2}\right]$} & $\mathrm{O}_{3} \mathrm{e} \mathrm{O}_{\text {amida }}$ & 41 \\
\hline${ }^{* *} 1.4 \mathrm{Fe}\left(\mathrm{ClO}_{4}\right)_{3}+2.5 \mathrm{TC}$ & EtOH- Teof & N.F & {$\left[\mathrm{Fe}(\mathrm{TC})_{2}\left(\mathrm{ClO}_{4}\right)_{3}\right]$} & $\mathrm{O}_{3} \mathrm{e} \mathrm{O}_{\text {amida }}$ & 41 \\
\hline${ }^{* * * *} \mathrm{HgCl}_{2}+$ OTC & $\mathrm{H}_{2} \mathrm{O}-\mathrm{MeOH}$ & N.F & {$\left[\mathrm{Hg}(\mathrm{OTC}) \mathrm{Cl}_{2}\right] \cdot 2 \mathrm{H}_{2} \mathrm{O}$} & $\mathrm{O}_{3} \mathrm{e} \mathrm{O}_{\text {amida }}$ & 35 \\
\hline
\end{tabular}

"Reação feita a $70{ }^{\circ} \mathrm{C}$. ** Reação feita entre $40-50{ }^{\circ} \mathrm{C} .{ }^{* * *}$ Cristais obtidos a $8{ }^{\circ} \mathrm{C}$. Teof $=$ trietil-ortoformato, N.F $=$ pH não fixado.

das espectroscópicas para diversas aplicações biológicas. ${ }^{40} \mathrm{Com}$ estes resultados, demonstra-se que a coordenação de metais de transição às tetraciclinas é ainda um campo de especial interesse, uma vez que as propriedades destes compostos ainda não foram totalmente exploradas.

\section{Mecanismo de ação e resistência}

O mecanismo de ação das tetraciclinas é bem estabelecido e há um consenso de que tetraciclinas se ligam a um sítio na subunidade $30 \mathrm{~S}$ do ribossomo bacteriano impedindo a ligação do aminoacil-t-RNA no sítio A do ribossomo, a adição de aminoácidos e, consequentemente, impedindo a síntese protéica. ${ }^{1,51}$ A Figura 4 apresenta um esquema do mecanismo da ação antibacteriana das tetraciclinas.

O mesmo mecanismo de ação tem sido proposto para a tigeciclina, sendo que as glicilciclinas se ligam cinco vezes mais fortemente ao ribossomo do que tetraciclina e minociclina, e esta ligação mais forte é responsável por contornar um mecanismo de ação de resistência às tetraciclinas que envolve a proteção ribossomal. ${ }^{4,52}$ A modificação em C9 deve provocar algum impedimento estérico que previne a substituição por proteínas que contêm o gene responsável pelo mecanismo de proteção ribossomal. ${ }^{2}$

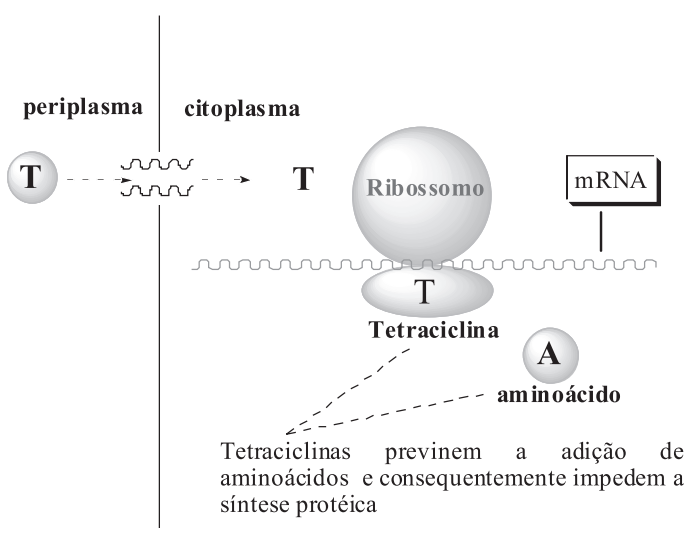

Figura 4. Esquema mostrando o mecanismo de ação das tetraciclinas
A emergência da resistência às tetraciclinas tem limitado seu uso no tratamento de infecções bacterianas em humanos. Diferentes mecanismos de resistência às tetraciclinas foram identificados e dois destes mecanismos com significado clínico serão discutidos: o efluxo do medicamento e a proteção ribossomal. ${ }^{52}$ No mecanismo por efluxo, Figura 5, comumente encontrado em bactérias Gram-negativas, há uma diminuição do acesso das tetraciclinas ao ribossomo por redução da concentração intracelular do antibiótico a um nível bem abaixo do necessário para a sua atividade. Neste mecanismo, proteínas transmembranares (Tet A) exportam tetraciclinas para fora da célula, provocando uma menor concentração da droga dentro das células bacterianas. A Tet A acopla o transporte de uma molécula de tetraciclina, na forma de um complexo de $\mathrm{Mg}(\mathrm{II})$, [ $\mathrm{TcMg}]^{+}$, de dentro para fora das células à entrada de um próton.

Com relação ao mecanismo por proteção ribossomal, proteínas citoplasmáticas protegem o ribossomo da ação das tetraciclinas e a síntese proteica prossegue normalmente. Em bactérias sensíveis, as tetraciclinas ligam-se ao ribossomo e mudam sua conformação padrão interrompendo a síntese proteica. Um dado curioso é que a minociclina permanece ativa contra alguns tipos específicos de bactérias que contêm o gene que confere este mecanismo de ação. ${ }^{52}$

$\mathrm{O}$ fenômeno da resistência às tetraciclinas tem aumentado e até mesmo a tigeciclina, que foi lançada recentemente, tem apresentado resistência em Proteae e em Pseudomonas aeruginosa e, por isso,

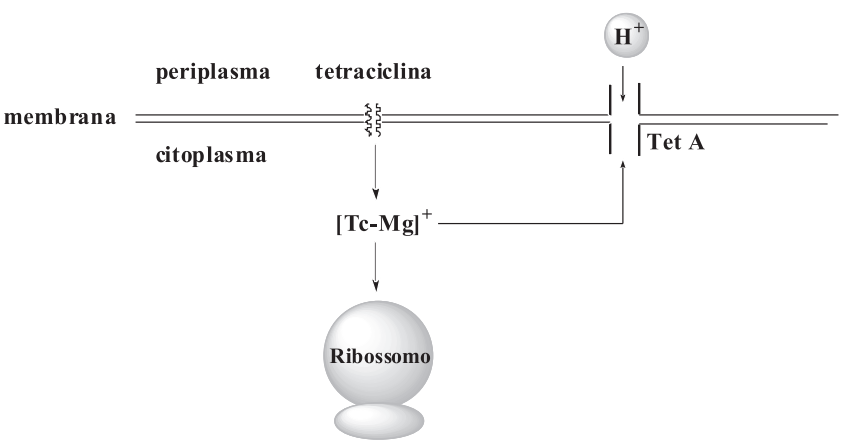

Figura 5. Esquema representando o mecanismo de resistência por efluxo 
esta droga não é recomendada para tratar infecções causadas por estas linhagens de bactérias. ${ }^{10,52}$ Cabe aqui ressaltar que o fenômeno da resistência é algo muito preocupante e que existem cepas resistentes a todos os agentes conhecidos atualmente, até mesmo outras classes de antibióticos com representantes lançados recentemente. Em consequência, é constante a necessidade de renovação do arsenal de antibióticos, especialmente aqueles com atividade em bactérias Gramnegativas uma vez que essas são menos sensíveis aos antibióticos. ${ }^{53}$

\section{Atividade antibacteriana}

Tetraciclinas possuem amplo espectro de atividade, mas para alguns micro-organismos, há grande diferença no grau de atividade. Em geral, as moléculas mais lipofílicas (hidrofóbicas) são mais ativas que as mais hidrofílicas e isto se deve à constituição lipoproteica das membranas biológicas. As substâncias químicas lipossolúveis possuem uma maior capacidade de transpor a membrana celular pelo processo de difusão passiva e, neste caso, sabe-se que tetraciclinas podem entrar na célula tanto por difusão passiva como por transporte ativo. ${ }^{2,54}$ Dentre as tetraciclinas, as glicilciclinas, minociclina e doxiciclina apresentam maior caráter lipofílico e são mais ativas se comparadas a outras tetraciclinas. Tetraciclinas são agentes bacteriostáticos e seu espectro de atividade se estende a numerosos organismos Gram-positivos e Gram-negativos, inclusive, organismos anaeróbicos, micobactérias (Mycobacterium marinum, Mycobacterium leprae) e protozoários, como a Entamoeba histolytica, Balantidium coli, Giárdia lamblia e Toxoplasma gondii. ${ }^{2}$

As atividades in vitro da tetraciclina, doxiciclina, minociclina e tigeciclina contra algumas bactérias Gram-negativas e Gram-positivas, assim como contra alguns organismos atípicos com relevância na clínica médica estão sumarizadas na Tabela 2. Nesta tabela é colocado o valor da $\mathrm{MIC}_{90}$, que é o valor mínimo de concentração da droga necessário para inibir em $90 \%$ o crescimento das bactérias.

Tigeciclina tem sido comparada a outros antibióticos e tem se mostrado mais ativa contra importantes linhagens bacterianas, como mostrado na Tabela 3 .

\section{Efeitos adversos e interação com outras drogas}

Tetraciclinas não apresentam efeitos colaterais severos e são consideradas drogas seguras. Em pacientes com problemas renais, tetraciclinas podem ser administradas, embora um ajuste na dose deva ser feito pelo médico. Os efeitos colaterais mais comuns às tetraciclinas, incluindo a tigeciclina, são náuseas, vômitos e diarréia, embora tigeciclina apresente níveis mais altos de incidência destes efeitos colaterais., ${ }^{2,4}$

Uma única restrição a estas drogas refere-se às mulheres grávidas e crianças em fase de crescimento, uma vez que tetraciclinas são depositadas nos ossos e dentes durante a calcificação, o que pode levar a um descoloramento dos dentes e a uma inibição do crescimento ósseo em crianças. ${ }^{55}$

Outros efeitos menos comuns são fotossensibilidade, que é caracterizada pelo aparecimento de manchas tipo queimadura de sol na pele, urticária, dor de cabeça, dor abdominal, hipertensão, febre, leucopenia leve, anemia, trombocitopenia. ${ }^{4}$

Tetraciclinas são fortes agentes quelantes e as suas propriedades antibacterianas e farmacocinéticas são afetadas pela coordenação de íons metálicos presentes no meio biológico. Sendo assim, durante o tratamento, a ingestão de suplementos minerais e multivitamínicos, alimentos ricos em cálcio, ferro, magnésio e outros minerais deve ser feita com um mínimo de $2 \mathrm{~h}$ antes ou depois da ingestão do antibiótico. Antiácidos e bicarbonato de sódio podem diminuir a absorção de tetraciclinas, pois aumentam o pH no estômago e, por isso, devem ser
Tabela 2. Atividade in vitro de tetraciclinas em organismos selecionados

\begin{tabular}{|c|c|c|c|c|}
\hline \multirow[t]{2}{*}{ Bactéria } & $\begin{array}{c}\text { Tetra- } \\
\text { ciclina }\end{array}$ & $\begin{array}{c}\text { Doxi- } \\
\text { ciclina }\end{array}$ & $\begin{array}{l}\text { Mino- } \\
\text { ciclina }\end{array}$ & $\begin{array}{l}\text { Tige- } \\
\text { ciclina }\end{array}$ \\
\hline & \multicolumn{4}{|c|}{$\mathrm{MIC}_{90}$} \\
\hline \multicolumn{5}{|l|}{ Gram-positivas } \\
\hline Staphylococcus aureus (MS) & 1 & 0,5 & 0,12 & 0,5 \\
\hline Staphylococcus aureus (MR) & 32 & 2 & 2 & 0,5 \\
\hline Streptococсиs pпеитопiаe(PS) & 32 & 8 & 8 & 0,125 \\
\hline Streptococсиs pneuтoniae (PR) & 64 & 8 & 16 & 0,125 \\
\hline Enteroccocus faecalis & 128 & 16 & 32 & 0,25 \\
\hline Enteroccocus faecium & 64 & 16 & 16 & 0,25 \\
\hline \multicolumn{5}{|l|}{ Gram-negativas } \\
\hline Haemophilus influenza & 0,5 & 3,1 & 0,25 & 1 \\
\hline Haemophilus influenza (BLP) & 1 & ND & 1 & 2 \\
\hline Klebsiella pneumoniae & 4 & ND & 4 & 1 \\
\hline Neisseria gonorrhoeae (PS, PR) & $>32$ & 2 & 32 & 1 \\
\hline Escherichia coli & $>8$ & ND & 8 & 0,5 \\
\hline \multicolumn{5}{|l|}{ Organismos atípicos } \\
\hline Chlamydia рпеитопіае & ND & 0,25 & ND & 0,125 \\
\hline Legionella pneumophila & $1-8$ & 4 & 4 & $\mathrm{ND}$ \\
\hline Mycoplasma pпеитопіае & 1 & 1,6 & 1 & 0,25 \\
\hline
\end{tabular}

$\mathrm{MIC}_{90}$ é a concentração mínima da droga $(\mathrm{mg} / \mathrm{mL})$ para inibir $90 \%$ do crescimento das bactérias. $\mathrm{ND}=$ não determinado. Dados retirados das ref. 1, 2, 9, 55 e 57.

Tabela 3. Atividade in vitro de tigeciclina e alguns antibióticos selecionados em algumas linhagens importantes clinicamente. Adaptado da ref. 4

\begin{tabular}{lcc}
\hline Bactéria & Droga & $\mathrm{MIC}_{90}(\mathrm{mg} / \mathrm{L})$ \\
\hline Enterococcus faecium & Tigeciclina & $\mathbf{0 , 0 6}$ \\
(vancomicina resistante) & Ampicilina & $>16$ \\
& Linezolida & 2 \\
& Penicilina & $>8$ \\
Staphylococcus aureus & Tigeciclina & $\mathbf{0 , 2 5}$ \\
(meticilina sensível) & Ampicilina & $>16$ \\
& Levofloxacina & 8 \\
& Linezolida & 4 \\
Staphylococcus aureus & Vancomicina & 1 \\
(meticilina resistante) & Tigeciclina & $\mathbf{0 , 2 5}$ \\
& Levofloxacina & $>32$ \\
& Linezolida & 4 \\
& Vancomicina & 1 \\
\hline
\end{tabular}

evitados. Neste aspecto, doxiciclina tem sido uma exceção, pois estudos mostram que a ingestão de alimentos ricos em cálcio, como leite, ou ingestão de substâncias que abaixam o pH gástrico não diminuem sua absorção. ${ }^{2}$ Pacientes que fazem uso de insulina devem ser monitorados, pois tetraciclinas podem reduzir a dose necessária em pacientes com diabetes mellitus. Uma restrição mais severa inclui o uso concomitante de tetraciclinas com o anestésico metoxiflurano, pois esta coadministração causa nefrotoxicidade e pode levar o paciente à morte. ${ }^{2}$

Cabe ressaltar que, para o antibiótico tigeciclina ainda não foram reportados, na literatura, estudos de interações com outras drogas importantes e que, no decorrer destes estudos, novas limitações podem aparecer.

\section{Uso de tetraciclinas e tigeciclina na terapia humana}

Tigeciclina foi lançada no mercado em 2005 pela Wyeth Pharmaceuticals para o tratamento de infecções de pele e intra-abdominais graves. A respeito da utilidade clínica deste antibiótico, o mesmo deverá ganhar novos usos, pois apresenta amplo espectro de ação, poucos efeitos colaterais e é ativo contra importantes linhagens bacterianas resistentes a vários antibióticos. Além disso, correntemente, há vários medicamentos sendo desenvolvidos para tratar infecções causadas por bactérias Gram-positivas, mas novos agentes para tratar infecções causadas por bactérias Gramnegativas estão em falta. ${ }^{1,4}$ 
Tabela 4. Uso corrente e potencial de tetraciclinas. Dados retirados das refs. $1,4,7-11,55-59$

Uso corrente de tetraciclinas incluindo tigeciclina na clinica médica.

Tetraciclinas

Infecções respiratórias causadas por Mycoplasma pneumoniae

Periodontites

Doença de Lyme (estágios 1 e 2)

Brucelose

Malária, diarréia de viajantes, cólera e leptospirose (prevenção e tratamento)

Conjuntivite e tracoma causados por Chlamydia trachomatis

Psitacose devido a Chlamydia psittaci

Febre maculosa, febre tifóide, febre Q e outras rickettisias causados por

Rickettsiae

Acne

Rosácea

Linfogranuloma venéreo, uretrite não-gonocócica e granuloma inguinal

Tigeciclina

Infecções graves de pele, tecidos moles e intra-abdominais

Outras indicações menos comuns

Tularemia

SIADH (demeclociclina)

MRSA (minociclina e tigeciclina)

Bartonelose

Sífilis

Carbúnculo (antraz maligno)

Orquiepididimite

Gastrite causada por Helicobacter pylory (tetraciclina em conjunto com

citrato de bismuto coloidal e metronidazol)

Uso potencial

Outras doenças de pele

Infecções causadas por protozoários

Artrite reumatóide

Doenças não infecciosas do cérebro

Doenças cardiovasculares

Câncer

Atualmente, tetraciclinas, principalmente doxiciclina e minociclina, estão sendo usadas para tratamento de diversos tipos de infecções causadas por bactérias Gram-negativas sensíveis. São também úteis no tratamento de diversos tipos de rickettsias, doenças sexualmente transmissíveis, úlceras pépticas causadas pelo Helicobacter pylori e no tratamento e prevenção de bactérias usadas como armamento em terrorismo biológico. ${ }^{2,8} \mathrm{~A}$ respeito da utilidade clínica das tetraciclinas, estudos recentes têm apontado possíveis novos usos, em especial para tetraciclina, doxiciclina e minociclina. Estes antibióticos têm uma série de propriedades não antibióticas que não foram exploradas durante algum tempo, incluindo propriedades anti-inflamatórias, imunossupressivas, inibição da lipase e colagenase, apoptose, angiogênese, entre outras. ${ }^{11}$ Quanto ao sucesso de tetraciclinas no tratamento de periodontites, não se sabe ainda se é devido às suas propriedades antibacterianas ou suas propriedades não antibacterianas, ou uma combinação das duas e isso tem sido tema de grande debate. ${ }^{8}$ Essas propriedades adicionais têm feito, das tetraciclinas, drogas atraentes para uso em uma variedade de situações não infecciosas, tais como acne, rosácea e outras doenças dermatológicas e não dermatológicas. ${ }^{56-60}$ A respeito destas propriedades não antibióticas das tetraciclinas, demeclociclina tem utilidade clínica adicional no tratamento de SIADH (Síndrome da Secreção Inapropriada de Hormônio Antidiurético). ${ }^{56} \mathrm{~A}$ Tabela 4 traz os usos de tetraciclinas e tigeciclina na clínica médica, assim como o uso potencial destas drogas. No que se refere ao potencial destas drogas, novos usos podem surgir e fazer com que tetraciclinas façam parte do tratamento de novas doenças, ou como droga de escolha, ou como parte da terapia. É interessante ressaltar que tetraciclinas ainda são uma opção de tratamento para diversas situações e como a tigeciclina apresenta boa atividade in vitro contra Neisseria gonorrhoeae, este uso pode ser recuperado em detrimento a outros antibióticos.

\section{CONSIDERAÇÕES FINAIS}

O uso da tetraciclina e seus derivados na clínica médica tem sido restringido devido ao aparecimento de resistência às tetraciclinas em um grupo variado de bactérias. A resistência apresentada pelas bactérias geralmente é cruzada a diversos tipos de classes de antibióticos, até mesmo aos lançados recentemente. Contudo, tetraciclinas são ainda bastante úteis no tratamento de diversos tipos de doenças. Tetraciclinas possuem propriedades adicionais que não foram exploradas no tempo de sua descoberta, tais como propriedades anti-inflamatórias e, por isso, novas aplicações tem emergido de diferentes laboratórios de pesquisa. Compostos de coordenação contendo tetraciclinas são promissores para uso na clínica médica, tanto no tratamento do câncer como no tratamento de doenças infecciosas.

\section{AGRADECIMENTOS}

Ao CNPq, à FAPEMIG e CAPES pelo apoio financeiro às pesquisas e às bolsas de pós-graduação concedidas.

\section{LISTA DE ABREVIAÇÕES}

FDA: Food and Drug Administration

ATP: Trifosfato de adenosina

RMN: Ressonância magnética nuclear

Uv - Vis: Espectroscopia de absorção no ultravioleta e visível

TC: Tetraciclina

ATC: Anidrotetraciclina

DOX: Doxiciclina

OTC: Oxitetraciclina

MR: Resistente à meticilina

MS: Sensível à meticilina

PR: Resistente à penicilina

PS: Sensível à penicilina

DNA: Ácido desoxirribonucleico

RNA: Ácido ribonucleico

MeOH: Metanol

\section{REFERÊNCIAS}

1. Shlaes, D. M.; Curr. Opin. Investig. Drugs 2006, 7, 167.

2. Zhanel, G. G.; Homenuik, K.; Nichol, K.; Noreddin, A.; Vercaigne, L.; Embil, J.; Gin, A.; Karlowsky, J. A.; Hoban, D. J.; Drugs 2004, 64, 63.

3. Speer, B. S.; Shoemaker, N. B.; Salyer A. A.; Clin. Microbiol. Rev. 1992, $5,387$.

4. Kasbekar, N.; Am. J. Health-Syst. Pharm. 2006, 63, 1235; Peterson, L. R.; Int. J. Antimicrob. Agents 2008, 32, S215.

5. Doan, T.-L.; Fung, H. B.; Metha, D.; Riska, P. F.; Clin. Ther. 2006, 28, 1079.

6. Agwuh, K. N.; MacGowan, A.; J. Antimicrob. Chemother. 2006, 58, 256.

7. Chopra, I.; Roberts, M.; Microbiol. Mol. Biol. Rev. 2001, 65, 260.

8. Roberts, M.; Clin. Infect. Dis. 2003, 36, 462.

9. Frampton, J. E.; Curran, M. P.; Drugs 2005, 65, 2623.

10. Jones, C. H., Petersen, P. J.; Drug Discovery Today: Therapeutic Strategies 2006, 3, 137; Nathwani, D.; Int. J. Antimicrob. Agents, 2009, 34 , S24.

11. Sapadin, A., N.; Fleischmajer, R.; J. Am. Acad. Dermatol. 2006, 54, 258.

12. Acharya, M. L.; Venitz, J.; Figg, W. D.; Sparreboom, A.; Drug Resist. Updates 2004, 7, 195. 
13. Foroodi, F.; Duivenvoorden, W. C.; Singh, G.; Anti-Cancer Drugs 2009, $20,115$.

14. Sagar, J.; Sales, K.; Dijk, S.; Taanman, J. W.; Seifalian, A.; Winslet, M.; World J. Surgical Oncology 2009, 7, 1.

15. French, G. L.; J. Chemother. 2008, 20, 3; Macgowan, A. P.; J. Antimicrob. Chemother. 2008, 62, 111.

16. Colaizzi, J. L.; Knevel, A. M.; Martin, A. N.; J. Pharm. Sci. 1965, 54, 1425.

17. Chartone-Souza, E.; Loyola, T. L.; Bucciarelli-Rodriguez, M.; Menezes, M. A.; Rey, N. A.; Pereira-Maia, E. C.; J. Inorg. Biochem. 2005, 95, 1001.

18. Guerra, W.; Silva, I. R.; Azevedo, E. A.; Monteiro, A. R. S.; BucciarelliRodriguez, M.; Chartone-Souza, E.; Silveira, J. N.; Fontes, A. P. S.; Pereira-Maia, E. C.; J. Braz. Chem. Soc. 2006, 17, 1627.

19. Lambs, L.; Decock-Le Révérend, B.; Kozlowski, H.; Berthon, G.; Inorg. Chem. 1988, 27, 3001 .

20. Duarte, H. A.; Carvalho, S.; Paniago, E. B.; Simas, A. M.; J. Pharm. Sci. 1999, 88,111

21. Pinsuwan, S.; Alvarez-Nunez, F. A.; Tabibi, E. S.; Yalkowsky, S. H.; Int. J. Pharm. 1999, 181, 31.

22. Lambs, L.; Brion, M.; Berthon, G.; Inorg. Chim. Acta 1983, 106, 151.

23. Brion, M.; Berthon, G.; Fourtellan, J. B.; Inorg. Chim. Acta 1981, 55, 47.

24. Jezowska-Bojezuk, M.; Lambs, L.; Kozlowski, H.; Berthon, G.; Inorg. Chem. 1993, 32, 428.

25. Brion, M.; Lambs, L.; Berthon, G.; Inorg. Chim. Acta 1986, 123, 61.

26. Everett, G. W.; Williamson, D. E.; J. Am. Chem. Soc. 1975, 97, 2397.

27. Everett, G. W.; Gulbis, J.; J. Am. Chem. Soc. 1975, 97, 6248.

28. Everett, G. W.; Gulbis, J.; Frank, C. W.; J. Am. Chem. Soc. 1976, 98, 1280.

29. Hirschy, L. M.; Van Geil, T. F.; Winefordner, J. D.; Kelly, N. R.; Schulman, S. G.; Anal. Chim. Acta 1984, 166, 207.

30. Cowan, J. A; Ohyama, T.; Inorg. Chem. 1995, 34, 3083.

31. Ghandour, M. A.; Azab, H. A.; Hassan, A.; Monatsh. Chem. (em alemão) 1992, 123, 51

32. Aly, A. A. M.; Strasser, A.; Vogler, A.; Inorg. Chim. Acta 2002, 336, 91.

33. Khan, A. M.; Musarrat, J.; Int. J. Biol. Macromol. 2003, 33, 49.

34. Khan, A. M.; Mustafa, J.; Musarrat, J.; Mutat. Res. 2003, 525, 109.

35. Jogun, K. H.; Stezowski, J. J.; J. Am. Chem. Soc. 1976, 98, 6018.

36. Paula, F. C.; Guerra, W.; Silva, I. R.; Silveira, J. N.; Botelho, F. V.; Vieira, L. Q.; Maia, E. C. P.; Chem. Biodiversity 2008, 5, 2124.

37. Karthikeyan, G.; Mohanraj, K.; Elango, K. P.; Trans. Metal Chem. 2004, $29,86$.
38. Baker, W. A.; Brown, P. M.; J. Am. Chem. Soc. 1966, 88, 1314.

39. Guerra, W.; Azevedo, E. A.; Monteiro, A. R. S.; Bucciarelli-Rodriguez, M.; Chartone-Souza, E.; Nascimento, A. M. A.; Fontes, A. P. S.; Le Moyec, L.; Pereira-Maia, E. C.; J. Inorg. Biochem. 2005, 99, 2348.

40. Aly, A. A. M.; Strasser, A.; Vogler, A.; Inorg. Chem. Commun. 2002, 5 , 411.

41. Mikuski, C. M.; Fleming, J.; Fleming, D. H.; Inorg. Chim. Acta 1988, $144,9$.

42. De Almeida, W. B.; Dos Santos, H. F.; Rocha, W. R.; Zerner, M. C.; J. Chem. Soc., Dalton Trans. 1998, 15, 2531

43. De Almeida, W. B.; Dos Santos, H. F.; Zerner, M. C.; J. Pharm. Sci. 1998, 87, 1101 .

44. Dos Santos, H. F.; De Almeida, W. B.; Zerner, M. C.; J. Chem. Soc. Perkins Trans. 1998, 2, 2519.

45. Dos Santos, H. F.; Xavier, E. S.; Zerner, M. C.; De Almeida, W. B.; J. Mol. Struct. (Theochem) 2000, 527, 193.

46. Dos Santos, H. F.; Marcial, B. L.; De Miranda, C. F.; Costa, L. A. S.; De Almeida, W. B.; J. Inorg. Biochem. 2006, 100, 1594

47. Wessels, J. M.; Ford, W. E.; Szymczak, W.; Schineider, S.; J. Phys. Chem. B 1998, 102, 9323.

48. Dos Santos, H. F.; De Almeida, W. B.; Zerner, M. C.; J. Pharm. Sci. 1998, 87, 190 .

49. Marcial, B. L.; Dissertação de Mestrado, Universidade Federal de Juiz de Fora, Brasil, 2009

50. Marcial, B. L.; Costa, L. A. S.; De Almeida, W. B.; Dos Santos, H. F.; J. Braz. Chem. Soc. 2008, 19, 1437.

51. de Paula, F. C. S.; Carvalho, S.; Duarte, H. A.; Paniago, E. B.; Mangrich, A. S.; Pereira-Maia, E. C.; J. Inorg. Biochem. 1999, 76, 221; Zakeri, B.; Wright, G. D.; Biochem. Cell Biol. 2008, 86, 124.

52. Roberts, M. C.; FEMS Microbiol. Lett. 2005, 245, 195.

53. Felmingham, D.; J. Chemother. 2005, 17, 5.

54. Schnappinger, D.; Hillen, W.; Arch. Microbiol. 1996, 165, 359.

55. Townsend, M. L.; Pound, M. W.; Drew, R. H.; Int. J. Clin. Pract. 2006, $60,1662$.

56. http://bulario.bvs.br, acessada em Agosto 2008.

57. Sum, P.-E.; Curr. Op. Chem. Biol. 2006, 10, 374.

58. Pasquale, T. R; Tan, J. S.; Rev. Anti-Infective Agents 2005, 40, 127.

59. Cunha, B. A.; Med. Clin. North. Am. 2006, 90, 1089.

60. Jordan. J.; Fernandez-Gomes, F. J.; Ramos, M.; Ikuta, I.; Aguirre, N.; Galindo, M. F.; Curr. Drug Delivery 2007, 4, 225. 